\title{
Changes in blink rate and ocular symptoms during different reading tasks
}

This article was published in the following Dove Press journal:

Clinical Optometry

Number of times this article has been viewed

\author{
Ali A Abusharha \\ Department of Optometry and Vision \\ Sciences, King Saud University, Riyadh, \\ Saudi Arabia
}

Background: Reading from tablets is fundamental to modern culture. This study measured differences in the blink rate and symptoms of ocular discomfort in healthy participants during reading from a tablet and a paper book.

Methods: Forty healthy, normal males subjects were recruited for this study. Subjects were video recorded during reading a text presented on an electronic device ( 9.7 inch tablet) and a hard copy format, for $15 \mathrm{~min}$. Ocular discomfort experienced during reading was scored using a visual analog scale. Each participant was examined performing one of the two tasks (randomized) on one visit and the other on a separate visit (crossover design). All subjects were evaluated before the reading tasks and every 5 min during 15 min of reading.

Results: The mean \pm standard deviation blink rate was $19.74 \pm 9.12 / \mathrm{min}$ at baseline. The blink rate decreased significantly under both reading conditions (to $11.35 \pm 10.20$ and $14.93 \pm 10.90$ / min when reading from a book and a tablet, respectively). There was no significant difference in the blink rate over $15 \mathrm{~min}$ during either type of reading. The mean discomfort symptom scores were 148 for the book and 134 for the tablet; both were significantly higher than baseline. A gradual increase in symptoms was found every 5 min during both types of reading.

Conclusion: The study confirmed that both the blink rate and ocular discomfort symptoms were strongly affected during performance of close visual tasks. Both reading conditions affected blinking; this may interfere with tear film dynamics. Such effects were reflected in the immediate development of ocular symptoms, which increased significantly during both types of reading.

Keywords: blink rate, tear film, reading tasks

\section{Introduction}

Normal blinking is essential to ensure the normal distribution of the tear film and to protect the ocular surface. ${ }^{1}$ Blinking abnormalities may result in poor tear distribution and hence cause damage to the ocular surface. ${ }^{2}$ Several studies have investigated the blink rate and the interval between blinks. It has been reported that the normal spontaneous blink rate is between 12 and $15 / \mathrm{min}^{3}{ }^{3}$ Other studies showed that the interval between blinks ranges from 2.8 to 4 and from 2 to $10 \mathrm{~s}^{3-5} \mathrm{~A}$ mean blink rate of up to 22 blinks/min has been reported under relaxed conditions. ${ }^{6}$ The variability in the blinking measurements of previous studies may be due to differences in experimental conditions.

The blink rate may be affected by many factors, including Parkinson's disease and corneal sensitivity disorders, that reduce the number of blinks and cause excessive ocular surface exposure. ${ }^{7}$ Additionally, patients with progressive supernuclear palsy have a reduced blink rate, ${ }^{8,9}$ perhaps attributable to a decrease in corneal sensitivity caused by loss of corneal nerves. ${ }^{8}$ Other factors such as changes in the gaze, lighting,
Correspondence: Ali A Abusharha Department of Optometry and Vision Sciences, King Saud University, Riyadh 12372, Saudi Arabia

Email aabusharha@ksu.edu.sa 
ambient temperature, and humidity may also affect the blink pattern. ${ }^{3}$

Ocular discomfort and visual fatigue are commonly reported during performance of close tasks such as reading, particularly when electronic devices are employed. Many studies have explored the relationship between eye fatigue and use of visual display terminals (VDTs). Symptoms of ocular discomfort and eye fatigue are common among VDT users. ${ }^{10,11}$ One previous study found that the symptom most frequently reported among office workers was tired eye (40\%); 30\% reported symptoms of dry eye and eye discomfort. ${ }^{12}$ The association between dry eye and the use of VDTs has also been well documented. ${ }^{13,14}$

Computers, tablets, and smartphones have become part of daily life and may increase the risk of developing many ocular symptoms. Spontaneous eye blinking has been found to be significantly reduced during use of computers and VDTs. ${ }^{15,16}$ To determine the effect of VDT use on blink rate, Schlote et $\mathrm{al}^{17}$ compared the blink rates of patients with dry eye during conversation and while reading a text on a video screen. The blink rate was significantly reduced from $17 / \mathrm{min}$ during conversation to $6 / \mathrm{min}$ while reading. ${ }^{17}$ Another study found significant reductions in the mean blink rate during the performance of a high-concentration task (reading rapidly changing letters on a computer display) compared with looking straight ahead in both normal subjects and patients with dry eye. ${ }^{18}$ The average reductions in blink numbers were $56 \%$ and $72 \%$ among normal subjects and patients with dry eye, respectively. ${ }^{18}$ In addition to a reduction in the number of blinks, an increase in the number of incomplete blinks during computer use has also been reported. ${ }^{18}$

Changes in the blink rate and pattern during computer use may cause ocular discomfort symptoms triggered, in turn, by a lack of adequate tear distribution. ${ }^{19}$ The purpose of the present study was to explore whether different reading tasks had any effect on the blinking pattern and/or induced ocular discomfort; we compared the magnitudes of the effects noted. Moreover, we also assessed intra-session variability in the blink rate and ocular comfort level, allowing us to monitor changes over time.

\section{Methods}

Forty healthy normal men (mean age, $24 \pm 12$ years) participated in the study. No subject had any history of ocular or systemic disease, binocular vision abnormality, or any signs or symptoms of dry eye (Ocular Surface Disease Index ${ }^{20}$ score of $<10$ points and non-invasive break-up time [HIRCAL grid] of $>10 \mathrm{~s}$ ). All subjects gave written informed consent. Ethical approval was obtained from College of Applied Medical
Sciences Ethics Committee. The study was conducted according to the Declaration of Helsinki ethical principles. ${ }^{21}$ Two visits were required: one to evaluate the blink rate and ocular discomfort while reading a paper book and the other to assess the same parameters while reading from an electronic device. The same text (in the same font and with the same line spacing and typeface) was presented under both conditions. All reading tasks were performed under the same ambient lighting and environmental conditions and at the same reading distance $(40 \mathrm{~cm})$. The electronic device had a screen size of 9.7 inches and a resolution of $1,024 \times 768$ pixels. A short visual analog scale questionnaire was applied every 5 min during reading to assess ocular discomfort. ${ }^{22}$ The subjects were asked to determine the severity of six specific symptoms: dryness, grittiness, stinging, tiredness, pain, and itching.

To measure the blink rate, we video recorded all subjects for $3 \mathrm{~min}$ before reading (baseline measurement). At baseline measurement, subjects were asked to relax and direct their gaze toward distance target $(3 \mathrm{~m})$. Video record was also performed for the entire 15 min of both reading tasks using a digital camera (Sony Cyber-Shot, DSC-W530). The number of blinks was manually counted in 5 min intervals.

Normality was tested using the Kolmogorov-Smirnov test. Paired sample $t$-test was used to compare baseline measurements with measurements for other reading conditions after $15 \mathrm{~min}$. To compare the measurements taken at $5 \mathrm{~min}$ intervals, repeated-measures analysis of variance and Tukey's post hoc test were used to compare normally distributed data. Friedman's test and post hoc Wilcoxon rank-sum test were used to evaluate data that were not normally distributed. Correlations between tear parameters were derived using Pearson's and Spearman's tests for data with normal and non-normal distributions, respectively.

\section{Results}

The mean and standard deviation of the blink rate and ocular symptoms assessed at different time points using different reading methods are shown in Tables 1 and 2 . The mean baseline blink rate was $19.74 \pm 9.12 / \mathrm{min}$. Significant fall in the blink rate was found after $15 \mathrm{~min}$ of reading either the book $(11.35 \pm 10.20 / \mathrm{min})$ or text on the electronic device $(14.93$ $\pm 10.90 / \mathrm{min}$ ) (Table 1 ). The blink rate after reading the book for $15 \mathrm{~min}(11.35 / \mathrm{min})$ was significantly lower than both the baseline value $(19.74 / \mathrm{min})(p=0.001)$ and that after reading electronic text for $15 \mathrm{~min}(14.93 / \mathrm{min})(p=0.029)$. No significant difference was seen in the blink rate among the three 5 min intervals $(5,10$, and $15 \mathrm{~min})$ when text was presented in either hard copy or on an electronic device (Figure 1). 
Table I Blink rate measured at different time points $(5,10$, and $15 \mathrm{~min})$ while performing reading task from electronic device and hard copy

\begin{tabular}{|c|c|c|c|c|c|c|}
\hline \multirow[b]{2}{*}{ Time point (min) } & \multicolumn{3}{|c|}{ Tablet } & \multicolumn{3}{|c|}{ Hard copy } \\
\hline & 5 & 10 & 15 & 5 & 10 & 15 \\
\hline Mean (blink/min) & 14.78 & 14.30 & 14.93 & 11.98 & 11.20 & 11.35 \\
\hline SD & 11.37 & 10.15 & 10.90 & 9.06 & 9.61 & 10.20 \\
\hline
\end{tabular}

Table 2 Ocular discomfort assessed at different time points (5, 10, and $15 \mathrm{~min})$ while performing reading task from electronic device and hard copy

\begin{tabular}{llllllll}
\hline & \multicolumn{2}{l}{ Tablet } & & & Hard copy & \\
\cline { 2 - 4 } Time point (min) & $\mathbf{5}$ & $\mathbf{1 0}$ & $\mathbf{1 5}$ & & $\mathbf{5}$ & $\mathbf{1 0}$ & $\mathbf{1 5}$ \\
\hline Mean (score) & 94.95 & 117.33 & 125.63 & & 97.38 & 119.63 & 138.05 \\
SD & 109.08 & 135.28 & 136.92 & & 108.20 & 128.63 & 156.10 \\
\hline
\end{tabular}
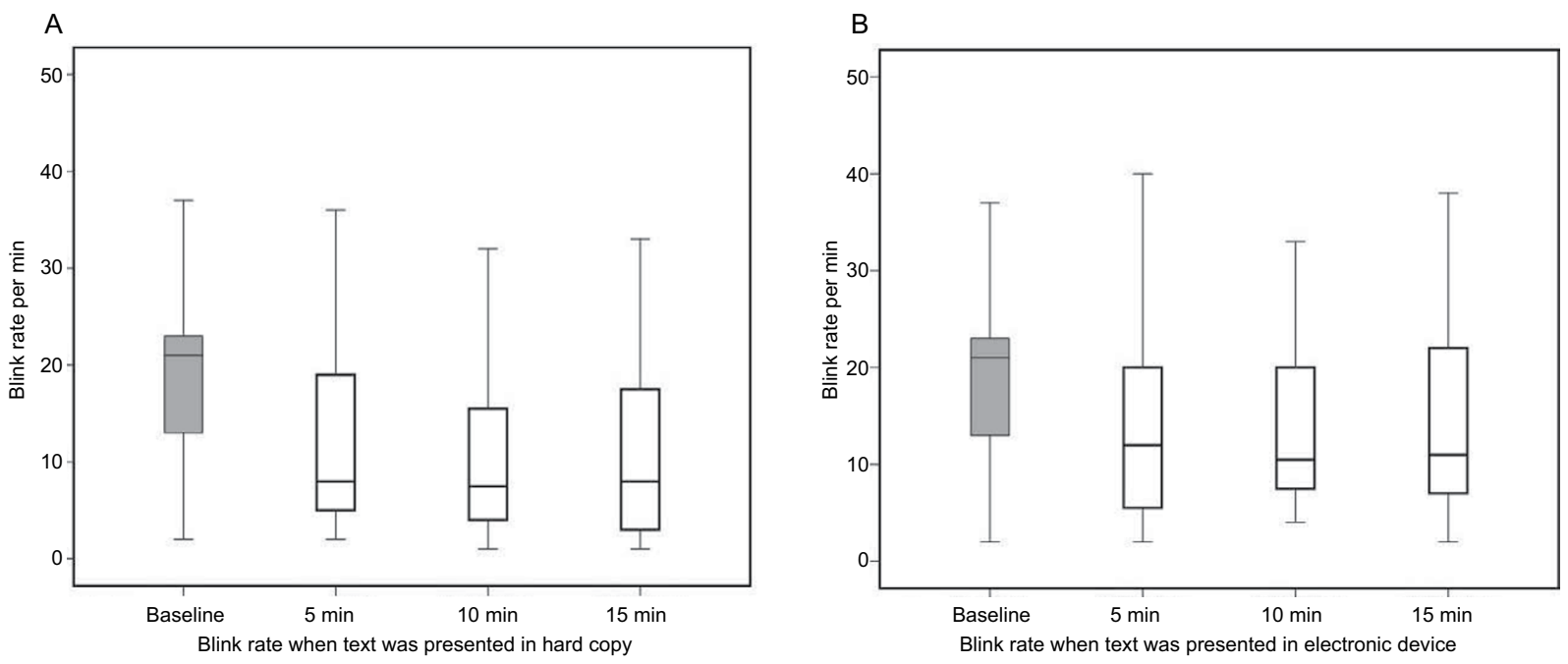

Figure I A box plot showing blink rate measured at different time points during reading from hard copy (A) and electronic device (B). The box represents the interquartile range that contains $50 \%$ of the values. The whiskers are lines that extend from the box to the highest and lowest values. The line across the box indicates the median value.

The symptom questionnaire showed that the ocular discomfort increased significantly from the baseline values at all time intervals when reading both hard and electronic copy $(p>0.001)$ (Table 2). Viewing text in either form resulted in a gradual increase in ocular discomfort over time (Figure 2). Although the mean ocular discomfort score was higher after reading hard copy for $15 \mathrm{~min}$ (score: 138), the difference was not significantly different from that associated with reading from the electronic screen (score: 125).

\section{Discussion}

The purpose of this study was to assess the effect of different reading conditions on the blink rate and ocular discomfort during performance of different reading tasks using hard copy and electronically presented text. Both the blink rate and the ocular discomfort were monitored during 15 min of reading using two different reading methods to evaluate the relationships between reading method, blink rate, and ocular discomfort symptoms. The intra-session variability in these parameters during the tasks was also monitored.

The mean spontaneous baseline blink rate was $19.74 \pm$ $9.12 / \mathrm{min}$, which is slightly higher than the values reported in recent studies. The spontaneous blink rate has been reported to range between 12 and $18 / \mathrm{min}^{3,23,24}$ The reason could be that, in our current study, we did not exclude subjects who might be classified as frequent blinkers (blink rate of $>21$ / $\mathrm{min}) .{ }^{25}$ Therefore, our average blink rate is slightly higher than those of previous studies.

The result of this study showed that the blink rate decreased significantly when reading either a book or text on an electronic device. This is in agreement with the findings of previous studies; blink rates dropped significantly under different reading conditions. ${ }^{26}$ One possible explanation is 

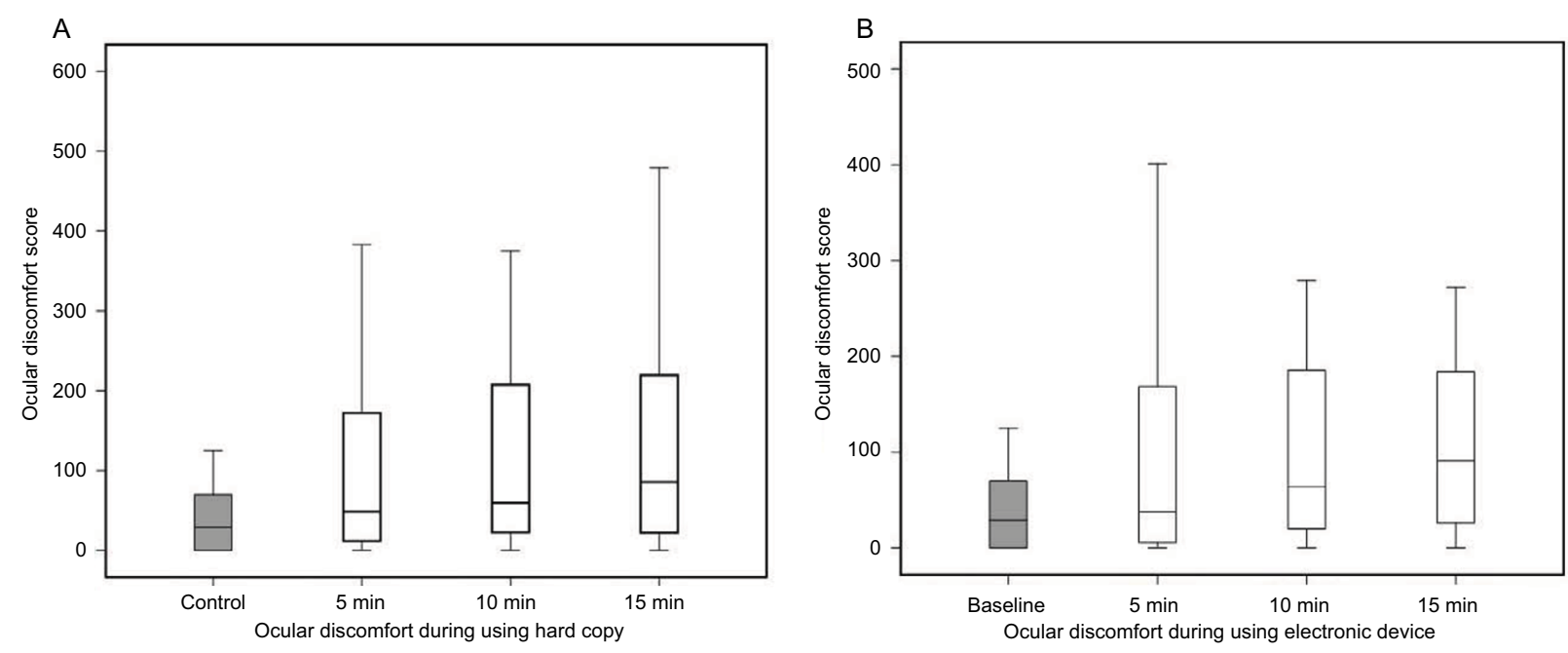

Figure 2 A box plot showing ocular discomfort symptoms measured at different time points during reading from hard copy (A) and electronic device (B). The box represents the interquartile range that contains $50 \%$ of the values. The whiskers are lines that extend from the box to the highest and lowest values. The line across the box indicates the median value.

that the attentional demand is higher during reading tasks, perhaps reducing the blink rate. ${ }^{23}$ Alternatively, use of the down-gaze position may be preferred during reading, which could in turn reduce the blink rate. ${ }^{3}$

We found that reading a book reduced the blink rate more than reading text on an electronic device; this is in agreement with the work of Argilés et al. ${ }^{23}$ They found that the blink rate was significantly lower when reading a book than text on an electronic device (9.7 inch tablet). Although the blink rate was higher when the electronic device was used, employment of an electronic device increased the incidence of incomplete blinks compared with hard copy reading condition. ${ }^{23}$

In the current study, changes in the blink pattern and ocular symptoms were observed during $15 \mathrm{~min}$ of reading. There was no evidence of changes in the blink rate or ocular symptoms during either type of reading, and no significant differences were evident among 5,10 and 15 min intervals. These findings emphasize that moving of the eye from the primary gaze position may be the main cause of reduction in the blink rate.

Previous studies have reported a reduction in blink rate when reading tasks performed in down gaze. It has been suggested that the reduction in blink rate during down-gaze viewing could be due to the decrease in the eyelid aperture. ${ }^{25}$ Therefore, decreased corneal exposure and less drying of ocular surface would be expected in comparison with primary gaze. ${ }^{23}$ This could be the reason for immediate reduction in blink rate found in this study during performing reading tasks.

It has also been shown that low contrast and small font resulted in eyelid squint and reduced blink rate. ${ }^{27}$ Other studies have reported a reduction in blink rate as the level of required concentration and cognitive demands increased when performing different visual tasks. ${ }^{18,28}$ Therefore, the reduction in blink rate observed in this study could also be resulted from the increased cognitive demands associated with close visual tasks.

Many studies have investigated the association between blink rate and tear dynamic when performing visual tasks. Previous study has investigated tear quality and tear blink rate when healthy subjects perform VDT tasks. It has been found that blink rate and tear stability were significantly affected during visual tasks. ${ }^{29}$ Another study has found a significant decrease in tear film thickness and meniscus high when subjects were asked to delay each blink as long as possible. ${ }^{30}$ Also, an increase in tear film evaporation rate and delay in blinking during the use of video display terminals have been reported. ${ }^{6}$ Therefore, adverse change in tear film parameters during close visual tasks could be the reason behind the rise of ocular discomfort symptoms.

An increase in ocular symptoms during use of electronic devices and VDTs is well documented. ${ }^{31,32}$ It has been reported that $70 \%$ of VDT users experience some visual symptoms. ${ }^{33}$ A significant increase in ocular discomfort was evident in the present study under both reading conditions. The visual analog scale scores and the questionnaire responses showed that ocular symptoms that developed during reading were more severe than those at baseline. However, no difference in the discomfort score was evident between the two methods of reading. Additionally, the ocular discomfort scores were similar at all time intervals $(0-5,5-10$, and $10-15 \mathrm{~min})$ during both types of reading. We found no correlation between the blink rate and ocular symptoms, in agreement with the 
findings of a previous study. No significant correlation was evident between incomplete blinking and eye symptom development during computer use. ${ }^{23}$

\section{Conclusion}

This study confirmed that both the blink rate and ocular comfort were strongly affected by close visual tasks. Both reading conditions influenced blinking; this may interfere with tear film dynamics. Such effects developed immediately as revealed by the significant increases in ocular symptoms. Our results found that the use of electronic devices for reading resulted in less ocular discomfort score compared to hard copy; however, this finding was not statically significant. Further studies with large sample size need to be carried out to determine the proper reading method that could result in less ocular discomfort.

\section{Acknowledgment}

The author extends their appreciation to the College of Applied Medical Sciences Research Centre and the Deanship of Scientific Research at King Saud University for its funding for this research.

\section{Disclosure}

The author reports no conflict of interest in this work.

\section{References}

1. Portello JK, Rosenfield M, Chu CA. Blink rate, incomplete blinks and computer vision syndrome. Optom Vis Sci. 2013;90(5):482-487.

2. Rahman EZ, Lam PK, Chu CK, Moore Q, Pflugfelder SC. Corneal sensitivity in tear dysfunction and its correlation with clinical parameters and blink rate. Am J Ophthalmol. 2015;160(5):858.e5-866.e5.

3. Doughty MJ. Consideration of three types of spontaneous eyeblink activity in normal humans: during reading and video display terminal use, in primary gaze, and while in conversation. Optom Vis Sci. 2001;78(10):712-725.

4. Fatt I, Weissman BA. Physiology of the Eye: An Introduction to the Vegetative Functions. Waltham: MA, Butterworth-Heinemann; 2013.

5. Volpe NJ. Adler's physiology of the eye: clinical application. J NeuroOphthalmol. 2004;24(4):348.

6. Tsubota K, Nakamori K. Dry eyes and video display terminals. N Engl J Med. 1993;328(8):584.

7. Suzuki K, Toyoda H, Hakamata N, Kimura N, Watanabe A, Kinoshita S. Non-invasive detection for Parkinson's disease with quantification of minute and subtle eyelid movements. Invest Ophthalmol Vis Sci. 2014;55(13):2566.

8. Reddy VC, Patel SV, Hodge DO, Leavitt JA. Corneal sensitivity, blink rate, and corneal nerve density in progressive supranuclear palsy and Parkinson disease. Cornea. 2013;32(5):631-635.

9. Martín-Montañez V, López-de la Rosa A, López-Miguel A, Pinto-Fraga J, González-Méijome JM, González-García MJ. End-of-day dryness, corneal sensitivity and blink rate in contact lens wearers. Cont Lens Anterior Eye. 2015;38(3):148-151.

10. Fenga C, Aragona P, Di Nola C, Spinella R. Comparison of ocular surface disease index and tear osmolarity as markers of ocular surface dysfunction in video terminal display workers. Am J Ophthalmol. 2014;158(1):41-48. e2.
11. Chisari G, Stagni E, Rampello L, Malaguarnera M, Chisari CG. The ocular surface in patients video display terminal (VDT). Acta Medica Mediterr. 2013;3(29):369-373.

12. Portello JK, Rosenfield M, Bababekova Y, Estrada JM, Leon A. Computer-related visual symptoms in office workers. Ophthalmic Physiol Opt. 2012;32(5):375-382.

13. Uchino M, Yokoi N, Uchino Y, et al. Prevalence of dry eye disease and its risk factors in visual display terminal users: the Osaka study. $\mathrm{Am} \mathrm{J}$ Ophthalmol. 2013;156(4):759-766.

14. Toda I, Fujishima H, Tsubota K. Ocular fatigue is the major symptom of dry eye. Acta Ophthalmol (Copenh). 1993;71(3):347-352.

15. Acosta MC, Gallar J, Belmonte C. The influence of eye solutions on blinking and ocular comfort at rest and during work at video display terminals. Exp Eye Res. 1999;68(6):663-669.

16. Blehm C, Vishnu S, Khattak A, Mitra S, Yee RW. Computer vision syndrome: a review. Surv Ophthalmol. 2005;50(3):253-262.

17. Schlote T, Kadner G, Freudenthaler N. Marked reduction and distinct patterns of eye blinking in patients with moderately dry eyes during video display terminal use. Graefes Arch Clin Exp Ophthalmol. 2004;242(4):306-312.

18. Himebaugh NL, Begley CG, Bradley A, Wilkinson JA. Blinking and tear break-up during four visual tasks. Optom Vis Sci. 2009;86(2): E106-E114.

19. Toomingas A, Hagberg M, Heiden M, Richter H, Westergren KE, Tornqvist EW. Risk factors, incidence and persistence of symptoms from the eyes among professional computer users. Work. 2014;47(3):291-301.

20. Schiffman RM, Christianson MD, Jacobsen G, Hirsch JD, Reis BL. Reliability and validity of the ocular surface disease index. Arch Ophthalmol. 2000;118(5):615-621.

21. World Medical Association. World Medical Association Declaration of Helsinki: ethical principles for medical research involving human subjects. JAMA. 2013;310(20):2191-2194.

22. Pearce EI, Jobson AS, Tandon S, Blades KJ. Dry eye questionnaires: a comparison of the responses made to visual analogue scale questionnaires with to those made to category based questionnaires. Invest Ophthalmol Vis Sci. 2005;46(13):4452.

23. Argilés M, Cardona G, Pérez-Cabré E, Rodríguez M. Blink rate and incomplete blinks in six different controlled hard-copy and electronic reading conditions. Invest Ophthalmol Vis Sci. 2015;56(11):6679-6685.

24. Casse G, Sauvage JP, Adenis JP, Robert PY. Videonystagmography to assess blinking. Graefes Arch Clin Exp Ophthalmol. 2007;245(12): 1789-1796.

25. Doughty MJ. Spontaneous eyeblink activity under different conditions of gaze (eye position) and visual glare. Graefes Arch Clin Exp Ophthalmol. 2014;252(7):1147-1153.

26. Chu CA, Rosenfield M, Portello JK. Blink patterns: reading from a computer screen versus hard copy. Optom Vis Sci. 2014;91(3):297-302.

27. Gowrisankaran S, Sheedy JE, Hayes JR. Eyelid squint response to asthenopia-inducing conditions. Optom Vis Sci. 2007;84(7):611-619.

28. Sheedy JE, Gowrisankaran S, Hayes JR. Blink rate decreases with eyelid squint. Optom Vis Sci. 2005;82(10):905-911.

29. Cardona G, García C, Serés C, Vilaseca M, Gispets J. Blink rate, blink amplitude, and tear film integrity during dynamic visual display terminal tasks. Curr Eye Res. 2011;36(3):190-197.

30. Palakuru JR, Wang J, Aquavella JV. Effect of blinking on tear dynamics. Invest Ophthalmol Vis Sci. 2007;48(7):3032-3037.

31. Nakazawa T, Okubo Y, Suwazono Y, et al. Association between duration of daily VDT use and subjective symptoms. Am J Ind Med. 2002;42(5): 421-426.

32. Miyake-Kashima M, Dogru M, Nojima T, Murase M, Matsumoto Y, Tsubota K. The effect of antireflection film use on blink rate and asthenopic symptoms during visual display terminal work. Cornea. 2005;24(5):567-570.

33. Aakre BM, Doughty MJ. Are there differences between 'visual symptoms' and specific ocular symptoms associated with video display terminal (VDT) use? Cont Lens Anterior Eye. 2007;30(3):174-182. 


\section{Publish your work in this journal}

Clinical Optometry is an international, peer-reviewed, open access journa publishing original research, basic science, clinical and epidemiological studies, reviews and evaluations on clinical optometry. All aspects of patient care are addressed within the journal as well as the practice of optometry including economic and business analyses. Basic and clinical

Submit your manuscript here: https://www.dovepress.com/clinical-optometry-journal research papers are published that cover all aspects of optics, refraction and its application to the theory and practice of optometry. The manuscript management system is completely online and includes a very quick and fair peer-review system, which is all easy to use. Visit http://www.dovepress. com/testimonials.php to read real quotes from published authors. 